\title{
XXXVI. The absorption of heat produced by the emission of ions from hot bodies: II
}

\section{H.L. Cooke \& O.W. Richardson F.R.S.}

To cite this article: H.L. Cooke \& O.W. Richardson F.R.S. (1913) XXXVI. The absorption of heat produced by the emission of ions from hot bodies: II, Philosophical Magazine Series 6, 26:153, 472-476, DOI: $10.1080 / 14786441308634992$

To link to this article: http://dx.doi.org/10.1080/14786441308634992

曲 Published online: 08 Apr 2009.

Submit your article to this journal

Џ Article views: 9

Q View related articles $\square$

Citing articles: 6 View citing articles 5 
which $m / \mathrm{H}=$ about 100 . This may point to an undiscovered common impurity which gives rise to heavy negative ions, but the reliability and accuracy of the measurements of $m / \mathrm{H}$ for these heavy ions are insufficient to establish such a conclusion at present.

In conclusion I wish to thank my assistant, Mr. E. S. Taylerson, for his help in carrying ont these experiments.

Palmer Physical Laboratory, Princeton, N. J.

XXXVI. The Absorption of Heat produced by the Emission of Ions from Hot Bodies : II. By H. L. Cook E, Assistant Professor of Physics, and O. W. Richandson, F.R.S., Professor of Physics, Princeton Lniversity*.

TN a recent paper $\dagger$ we have shown that when a current of negative electrons is allowed to flow from a heated filament of osmium, there is an absorption of heat which is equal in amount to the energy required to drive the escaping electrons through a potential difference of $4 \cdot 7$ volts. The present paper deals with similar experiments which we have made with lime-coated platinum wires and with tungsten wires. Neither the apparatus used nor the method of experimenting has been changed in any important particular, so that it will be sufficient to refer to the former paper for their description and simply to record the results which have been obtained. We shall also use the same notation as before.

The behaviour of lime coated platiıum wires is of particular interest since it was with this combination of substances that the first attempts were made, by Wehnelt and his pupils $\neq$, to detect the effect under investigation. Our experiments agree with theirs in showing that the phenomena exhibited by lime-coated platinum wires do not exhibit any evident relationship with the theory of these effects. Their behaviour is quite different from that of the osmium and tungsten wires. In the case of the latter substances the

* Communicated by the Authors.

$\dagger$ Phil. Mag. vol. xxv. (1913) p. 624.

I Cf. Wehnelt \& Jentzsch, Ann, der Phys. vol. xxviii. p. 537 (1909), and Schneider, Ann. der Phys. vol, xxxvii. p. 569 (1912). 
thermal changes which take place when the thermionic current is turned on or off all occur within a few seconds. In fact in our experiments the time within which these changes were completed was comparable with the period of the galvanometer used in the Wheatstone's bridge. With the lime-coated platinum wires, under otherwise identical circumstances, it was questionable whether the changes were complete in a time comparable with ten minutes. The precise nature of the changes also depended rather definitely on the mode of preparation of the lime-coated surface. Different wires presented different peculiarities of behaviour, but there were certain features common to the behaviour of all the wires examined, which were briefly as follows:Upon allowing conditions to become steady, with the Wheatstone's bridge balanced it was found that turning on the thermionic current caused the galvanometer to indicate a decrease in the resistance of the wire under examination. The nature of this change was not, however, similar to that observed in the case of osmium and tungsten wires, but rather indicated a fairly steady rate of decrease in the resistance with the time. In the case of some wires examined this rate of decrease of resistance due to the flow of the thermionic current showed no clear signs of abatement at the end of an interval of fifteen minutes. This peculiarity of behaviour could not be ascribed to a natural sluggishness of the wires to adjust themselves to alternations in the thermal or energy conditions, for when the rate of supply of electrical energy was suddenly altered by increasing the heating current in the manner described in our previous paper, the galvanometer indicated that the corresponding resistance changes were complete in considerably less than thirty seconds, as in the case of the osmium and tungsten wires. With regard to the magnitude of the steady rate of decrease of resistance observed when the thermionic current was flowing, it was found that the deflexion of the galvanometer produced by ten minutes flow of thermionic current yielded a value of the apparent loss of energy per unit current of considerably over one hundred equivalent volts, the calculations being made on the assumption that the galvanometer deflexion was due to a true cooling effect brought about by the thermionic emission, as demanded by the theory of the experiments. It seems evident that this change in resistance is not to be ascribed to the cooling effect sought for in this investigation. This conclusion is supported by the fact that upon stopping the thermionic 


\section{Profs. Cooke and Richardson on Absorption of}

current the galvanometer did not always indicate an increase in resistance corresponding to a recovery from the cumulative decrease brought about by the previous thermionic emission, although in most cases such a recovery was undoubtedly indicated. Attempts were made to detect the cooling effect sought by trying to detect a sudden initial decrease of resistance of the wire caused by turning on the thermionic current in addition to the cumulative effect just described, but without success. Our conclusion with regard to limecoated platinum wires is that if the effect sought is present it is masked by the larger cumulative effect. No attempts were made to examine this cumulative effect in great detail, but it is perhaps worth mentioning that the data obtained in the course of this investigation would be satisfactorily explained on the assumption that this effect is due to an increase in the radiating power of the surface of the lime brought about by electrolytic effects in the lime occasioned by the passage through it of the thermionic current.

\section{Experiments with Tungsten Wires.}

The behaviour of this material resembles that of the osmium filaments already investigated and is quite different from the lime-conted wires. The change of resistance due to turning the thermionic current on or off is complete in a few seconds, and the cooling effect when the current is turned on is equal to the heating effect when the current is turned off.

The ductile tungsten wire used was $3 \cdot 3 \mathrm{~cm}$. long and $0.00375 \mathrm{~cm}$. in diameter. It was kindly presented to us by Dr. W. R. Whitney, of the General Electric Co. After being welded electrically in hydrogen to stout german-silver leads, it was sealed into a glass tube so as to pass axially down a cylindrical electrode of copper foil $3.5 \mathrm{~cm}$. in diameter. The ends of the latter were boxed in by sheets of the foil with a small hole in the centre, so that the electrode practically enclosed the hot wire. The tube was exhausted and heated for several hours in a vacuum furnace at a temperature of $550^{\circ}-570^{\circ} \mathrm{C}$. With the tube at $250^{\circ}-300^{\circ} \mathrm{C}$. the wire was glowed out at above $2500^{\circ} \mathrm{K}$. in a liquid air and charcoal vacuum until the evolution of gas was not more than $10^{-3}$ c.c. $\times \mathrm{mm}$. of mercury in 5 minutes. It was then sealed off for use. The measurements were carried out exactly as described in the previous paper. Some of the experimental data are given, using our former notation, in the following table :- 
Heat produced by Emission of Ions from Hot Bodies. 475

\begin{tabular}{|c|c|c|c|c|c|c|c|c|c|c|}
\hline$\theta^{\circ} \mathbf{K}$. & $\mathrm{D}_{\mathrm{T}}$ & $D_{\mathrm{E}}$ & $\begin{array}{c}\mathrm{T} \\
\mathrm{amp} \\
\times 10^{-}\end{array}$ & $\begin{array}{c}i_{1} \\
\operatorname{amp} .\end{array}$ & $\underset{\text { ohms. }}{\mathbf{R}}$ & $\begin{array}{c}V \\
\text { volts. }\end{array}$ & $\underset{\mathrm{F} \rightarrow \mathrm{Sil}}{(\mathbf{S})}$ & $\underset{\substack{\text { sh. } \\
(2)}}{F}$ & $\underset{\mathbf{F} \rightarrow \mathrm{S}}{\mathbf{S t a n}}$ & $\underset{\substack{\text { Sh) } \\
\rightarrow(4)}}{\text { F }}$ \\
\hline $\begin{array}{c}1960 \\
\not " \\
19380\end{array}$ & $\begin{array}{r}13 \cdot 54 \\
9 \cdot 45 \\
8 \cdot 55 \\
2 \cdot 66\end{array}$ & $\begin{array}{l}1 \cdot 64 \\
1.70 \\
1.65 \\
1.67\end{array}$ & $\begin{array}{l}572 \\
603 \\
632 \\
752\end{array}$ & $\begin{array}{r}\cdot 343 \\
\cdot 343 \\
\cdot 342 \\
\cdot 342\end{array}$ & $\begin{array}{l}16 \cdot 6 \\
16 \cdot 26 \\
16 \cdot 3 \\
16 \cdot 51\end{array}$ & $\begin{array}{l}23 \cdot 8 \\
23 \cdot 8 \\
23 \cdot 8 \\
23 \cdot 8\end{array}$ & $4 \cdot 37$ & 4.95 & $1 \cdot 14$ & 7.92 \\
\hline $\begin{array}{c}1865 \\
", \\
"\end{array}$ & $\begin{array}{r}.84 \\
2 \cdot 64 \\
2 \cdot 86 \\
5 \cdot 43\end{array}$ & $\begin{array}{l}1.46 \\
1.46 \\
1.47 \\
1.50\end{array}$ & $\begin{array}{l}176 \cdot 9 \\
161 \cdot 5 \\
182 \cdot 7 \\
207\end{array}$ & $\begin{array}{l}\cdot 315 \\
\cdot 320 \\
\cdot 320 \\
.320\end{array}$ & $\begin{array}{l}15^{\cdot} \cdot 71 \\
15 \cdot 43 \\
15^{\cdot} \cdot 43 \\
15 \cdot 70\end{array}$ & $\begin{array}{l}23 \cdot 7 \\
23 \cdot 7 \\
23 \cdot 7 \\
23 \cdot 7\end{array}$ & $4 * 47$ & $4 \cdot 42$ & $1 \cdot 3 !$ & $7 \cdot 37$ \\
\hline $\begin{array}{c}\text { 1935 } \\
, " \\
",\end{array}$ & $\begin{array}{r}10 \cdot 51 \\
4.96 \\
6.09 \\
2 \cdot 17\end{array}$ & $\begin{array}{l}1 \cdot 572 \\
1 \cdot 564 \\
1.825 \\
1.594\end{array}$ & $\begin{array}{l}437 \cdot 1 \\
420 \cdot 8 \\
433 \cdot 3 \\
49 y \cdot 5\end{array}$ & $\begin{array}{l}338 \\
\cdot 338 \\
\cdot 338 \\
\cdot 338\end{array}$ & $\begin{array}{l}16.22 \\
15.94 \\
15.95 \\
16.22\end{array}$ & $\begin{array}{l}23 \cdot 7 \\
23 \cdot 7 \\
23 \cdot 7 \\
23 \cdot 7\end{array}$ & $3 \cdot 88$ & 3.80 & $1 \cdot 45$ & $7 \cdot 87$ \\
\hline
\end{tabular}

In the units in which $D_{\mathrm{T}}$ and $\mathrm{D}_{\mathrm{E}}$ are expressed in the above table the insensitiveness of the galvanometer was $1 \cdot 24 \times 10^{-7}$ and equation (13) of the former paper becomes

$$
\partial \mathrm{R}_{e}=1 \cdot 24 \times 10^{-7}[\mathrm{G}+100 \mathrm{R}(1 \cdot 01+\cdot 001 \mathrm{G})] \times \mathrm{D}_{\mathrm{E}} \cdot\left(13^{1}\right)
$$

After substituting the above numbers in our former equation (12) the resulting values of the cooling effect in equivalent volts at the temperatures named are :-

\begin{tabular}{|c|c|c|c|c|}
\hline$\theta_{0} \mathrm{~K}$ & 1865 & 1935 & 1965 & $\begin{array}{c}\text { A verage. } \\
1922\end{array}$ \\
\hline$\phi(1+2)$ & $4 \cdot 3 \pm$ & $3 \cdot 73$ & $4 \cdot 57$ & $\left.4 \cdot 21_{3}\right)$ \\
\hline$\phi(3+4) \ldots$ & $4 \cdot 49$ & $4 \cdot 35$ & $3 \cdot 97$ & $4 \cdot 27$ \\
\hline Means ...... & $4 \cdot 41_{5}$ & $4 \cdot 04$ & $4 \cdot 27$ & $4 \cdot 24$ \\
\hline
\end{tabular}

Higher values than those just given were obtained at higher temperatures and large thermionic currents, but the measurements under these conditions are subject to large errors which we have not yet succeeded in disentangling.

'The mean of the above values of $\phi$, viz. $4 \cdot 24$ volts, compares with 4.7 volts for osmium found in the former experiments. The thermionic current $i$ from the above tube at different temperatures $\theta$ has been measured by 0 . W. Richardson and K. K. Smith. It was found to follow the formula $i=\mathrm{A} \theta^{2} e^{-b / \theta}$, where $\mathrm{A}$ and $l$ are constants, from $1500^{\circ} \mathrm{K}$. to $2300^{\circ} \mathrm{K}$. By putting $b=\phi / \mathrm{R}$ these measurements gave $\phi=3.585$ volts, a lower value than that given by the cooling 
effect. However, later measurements which they made after the tube had been differently treated led to a higher value of $b$, and the investigation referred to is not yet completed, so that the difference in the value of $\phi$ given by the two methods may not be significant.

In concluding we wish to correct an erroneous statement on p. 643 of the former paper. Maturer consideration has led us to conclude that the small systematic error referred to in the last paragraph but two makes the measured value of $\phi$ too large at high temperatures and not too small as is there stated. In consequence we do not now regard the suggested increase of $\phi$ with $\theta$ as definitely established by the experiments. They are, in fact, insufficiently accurate for the purpose.

We are glad to be able to take this opportunity of thanking Messrs. W. P. Schenck and W. R. Wensley, who took most of the observations under our direction.

Palmer Physical Laboratory,

Princeton, N.J.

\section{On the Constitution of Atoms and Molecules.} By N. Bонr, Dr.phil. Copenhagen* .

\section{Part II.-Systems containing only a Single Nucleus $\dagger$.}

\section{$\S 1$. General Assumptions.}

GOLLOWING the theory of Rutherford, we shall assume 1 that the atoms of the elements consist of a positively charged nucleus surrounded by a cluster of electrons. The nucleus is the seat of the essential part of the mass of the atom, and has linear dimensions exceedingly small compared with the distances apart of the electrons in the surrounding cluster.

As in the previous paper, we shall assume that the cluster of electrons is formed by the successive binding by the nucleus of electrons initially nearly at rest, energy at the same time being radiated away. This will go on until, when the total negative charge on the bound electrons is numerically equal to the positive charge on the nucleus, the system will be neutral and no longer able to exert sensible forces on electrons at distances from the nucleus great in comparison with the dimensions of the orbits of the bound electrons. We may regard the formation of helium from a rays as an

* Communicated by Prof. E. Rutherford, F.R.S.

$\dagger$ P'art I. was published in Phil. Mag. xxri. p. 1 (1913). 